\title{
A anunciaçáo da morte do herói
}

Italia Bonadio

Resumo: Este estudo se propõe a faz̧er a tradução e a análise do poema Xuāngào (宣告) escrito pelo poeta Bei Dao no final do século XX. A ideia é tornar possivel a leitura de um complexo e belo poema chinês para os falantes de Lingua Portuguesa e também desmistificar a cultura chinesa como pacifica ou alienada. Através da arte busca-se entender como funciona o pensamento de um povo não para classificá-lo como exótico, mas para perceber que acima de tudo é humano.

Palavras-chave: Poesia chinesa do sec. XX, Bei Dao, herói chinês.

Bei Dao ${ }^{1}$ nasceu em 1949, participou da guarda vermelha durante os primeiros anos da Revolução Cultural, começou a escrever em 1970 integrando um grupo de poetas que se manifestava contra a revolução da qual ele mesmo fora membro. Sua história aproxima-se, de certo modo, da de Yu Luoke, a quem seu poema é dedicado. Este intelectual, impossibilitado de seguir seus estudos em nível universitário por ter origens em uma família de tradição intelectual e supostamente de "ideias direitistas", torna-se um autodidata e em 1966 escreve um tratado manifestando-se contra as ideias deterministas das classes de origem. Segundo estas, as famílias do proletariado seriam privilegiadas em contraposição às dos antigos intelectuais, as quais seriam depreciadas e envergonhadas. Ele mesmo imprime seu tratado e se encarrega da divulgação inicial. Posteriormente, este será editado e sua opinião solicitada e discutida em nível nacional. A visibilidade

1 Bei Dao é o pseudônimo de Zhao Zhenkai, poeta contemporâneo chinês que após deixar a guarda vermelha, foi obrigado à reeducação pelo governo durante a revolução cultural (1966-1976) trabalhando na construção civil. Participou de um grupo chamado de “Poetas Nebulosos" (朦胧诗 ménglóng shì), o qual acaba influenciando movimentos pró-democráticos e, após o massacre na Praça da Paz Celestial em 1989, o poeta é exilado, ganhando permissão para retornar à China somente em 2006. Ganhou vários prêmios literários como o prêmio Argana de poesia internacional no Marrocos, o prêmio Tucholsky da associação de escritores suecos, o prêmio liberdade de escrita Barbara Goldsmith, além de ser membro honorário da Academia Americana de Artes e Letras. 
nacional é justamente o que faz com que seja preso em 1968 sob a acusação de organizar grupos contrarrevolucionários, acusação que o levará a ser executado em março de 1970 aos 27 anos de idade. Em 1979 sua imagem é reabilitada pelo tribunal de Pequim, sendo hoje tido como mártir.

Ao fazer sua dedicatória, Bei Dao está ciente das tragédias pelas quais a Revolução Cultural Chinesa foi responsável. Tendo atuado na guarda vermelha, o poeta conhece profundamente o pensamento deste movimento ao qual renunciou. Ele mesmo sofre com a crítica e o exílio por expressar sua opinião através da arte e então se aproxima bastante da personalidade a quem faz a dedicatória, assim o eu-lírico do poema se constitui numa junção das duas personalidades. O eu do poema é um tipo de pessoa, aquela que se envolveu. Esse intelectual envolvido era desejado na China, porém, com o Partido Comunista no poder, as orientações são para que a arte faça parte da política e principalmente elogie a Revolução. Diante da longa tradição imperial, o novo poder é visto como libertário, mas continua inquestionável, não permitindo nem mesmo o que Fairbank e Goldman (2008) chamam de "oposição leal"; ou seja, uma crítica que fale sobre os problemas, mas sem deixar de ser nacionalista não encontra possiblidade de existência, o que o governo oferece como possibilidade de expressão artística é somente o elogio, positivando a ação governamental. Para Michelle Yeh (1993) a grande vantagem dessa poesia moderna é justamente ser uma poesia marginal, fora das orientações governamentais, o que, nestas circunstâncias, dá vazão a criatividade e lhe atribui um grande poder, também associado à responsabilidade.

Em seu primeiro verso o eu-lírico inicia com uma dúvida (talvez) a qual é também uma previsão, esta ansiosamente esperada, o que demonstra o advérbio "finalmente". Apesar da espera o poeta parece não ter se preparado, já que não fez um testamento, deixa como herança somente um objeto de escrita, de arte. O ideograma 笔 b̆ carrega consigo não apenas a ideia de caneta, mas de qualquer objeto usado para a escrita ou pintura, sendo muitas vezes traduzido como 'pincel'. O fato de ter deixado seu objeto de trabalho como herança junto a um testamento ainda não escrito simboliza todos os seus textos, suas opiniões, que deveriam ser desenvolvidas, mas foram caladas por impossibilidade, por força. Também representa as novas gerações da família que não virão, já que ser de uma família de intelectuais é um problema. A caneta deixada para a mãe não produzirá novos poetas para serem massacrados, não desta família, será devolvida à tradição e lá permanecerá esquecida. O interessante deste verso é que se as construções sintáticas forem desmontadas, o que permite a língua chinesa, e as unidades de sentido resseparadas, chega-se a 留 liú com o sentido de 'permanecer' e 下笔 xiäb̆ como 'começar a escrever'. Deste modo o poeta não mais 'deixaria somente uma 
caneta', mas 'permaneceria iniciando sua escrita', mesmo após a morte, mesmo que tentem calá-lo, há aí um movimento de recomeço, de novas possibilidades. O testamento que em sua brancura carrega uma mensagem e o poema que carrega ambiguidade.

No quarto verso o eu-lírico enfatiza que "nem" será herói, e aí se percebe uma resistência em assumir esse papel, gostaria de não precisar fazê-lo e, neste momento, mesmo havendo necessidade não há vontade, já que a época não permite esta posição. A expressão 并不是 bìng bù shì, traduzida por “nem”, trás aqui o sentido de "não é que", como se o eu-lírico já previsse que seria visto como portador de atitudes heroicas e simplesmente rejeitasse esta posição de ser inspiração a outros heróis, ele deseja poder levar uma vida comum, sem fama, sem reconhecimento pela força, sem morte. Há o desejo do poeta de permanecer simplesmente como uma pessoa comum, porém, talvez a menção, mesmo na negativa, de não ser uma época para heróis faça com que surja a inspiração entre os leitores de assumir uma atitude diante de sua época. Assim, o herói é aquele que luta por valores humanos, além de qualquer política. Este desejo, de não ser herói e nem inspiração para outros heróis, fortalece-se se os heróis, em uma ambiguidade, forem aqueles apontados pelo governo como tais e não o são por merecimento. O poeta procura formar o eu-lírico como um sujeito digno de respeito, tanto por suas reflexões quanto por seus hábitos e acaba por alertar sobre a não identidade das pessoas a sua volta, separando-os nas simples funções de viver ou morrer, fato que resulta em desintegração de valores, de personalidade, e em alienação. $\mathrm{O}$ poder de encarceramento dentro dessa "era" da qual não há como escapar aparece também na sintaxe através das partículas 在 zai 'em' e 里 $\pi{ }^{\prime}$ 'dentro' que iniciam e finalizam o verso, respectivamente, sufocando e enfatizado a 'era sem heróis'.

O desejo de ser um homem comum é apontado inclusive por parte da gramática, o autor explicita o numeral - yì 'um', o qual obrigatoriamente tem de ser seguido de classificador. Essa uma 'unidade de pessoa' nos dá, às vezes, a sensação de solidão, já que o próprio adjetivo 'sozinho' pode ser escrito como 个人 yì gè rén, isso também porque o eu-lírico percebe-se cercado de alienados. É interessante notar que o classificador de pessoa 个 gè é um dos classificadores mais usados na língua chinesa, não só em quantidade, mas para uma grande variedade de substantivos, sendo assim quase um genérico. Desse modo, a 'personagem' ganha ainda mais ares de comum, principalmente se considerarmos que o poeta poderia ter optado pelo classificador 位 wè̀, porém atribuiria estatus e polidez ao sujeito. Este, portanto, realmente não deseja o heroísmo, mas pelas características e inclusive pelas impossibilidades da época, acaba por ser o único herói, o herói solitário. O autor sugere com isto que Yu Luoke não queria ser transformado em 
um mártir, que não era necessário, somente tinha uma noção diversa de pensar, uma noção diversa de justiça. O verbo 做 zuò dando a ideia de 'fazer, desempenhar função de', retira definitivamente o eu-lírico do campo do solitário egoísta, do ser para si próprio, fazendo com que assuma um papel, um lugar social. Papel social este também explicitado pela partícula substantivadora 者 ₹̧ę na segunda estrofe, a qual transforma nascer em nascentes, em viventes, e a morte em 'morrentes', agonizantes. Ou seja, não há simplesmente a vida e a morte, mas as pessoas que sofrem e estão momentaneamente sofrendo estas ações. Aqueles que morrem lentamente por não exercer a vida em seu sentido 'verdadeiro', morrem a cada vez que deixam de 'ser uma pessoa', vivem já sem vida própria, sem opinião própria. A grande questão apresentada no poema é que os papéis sociais, os personagens, são ocupados por pessoas, por gente de verdade, os quais deveriam ter sua individualidade respeitada e não somente serem agregados a uma classe.

$\mathrm{Na}$ segunda estrofe como visto acima o poeta passa a abordar a ideia de ação, também inicia a falar de espaço, deixando um pouco de lado a noção de tempo, já bem aprofundada na primeira estrofe. O poema carrega então características da narrativa tendo como principais personagens aquele que não deseja ser herói e seus executores. Porém, seguindo as formas da poesia clássica chinesa este se mantém sintético, narrando um evento pontual de modo bastante tenso e por isso poderíamos aproximá-lo daquilo que se faz na tradição ocidental do conto e da fotografia. Reina aqui a característica da impressão impactante, a qual perpassa toda a poesia chinesa, a observação de uma pintura em que o autor nos narra o caminho que os olhos fazem ao compor uma visão total da obra. Porém, diferente da poesia tradicional, o poeta assume aqui sua subjetividade, falando de si e marcando isto explicitamente com o pronome de primeira pessoa 我 $w o ̌$, o qual se repete várias vezes, e logo após o pronome apresenta seus desejos e possibilidades como indivíduo. A natureza que monta o cenário não aparece mais como sugestão condensada de sentimentos como na literatura clássica e sim como consequência da ação do indivíduo em seu contexto específico. O poema agora surge como o resultado da vida, como um objeto de intensa autorreflexão e de resultados muito mais trágicos do que triunfantes. Esta subjetividade do poeta é tida como indesejada pelo governo da época, pois o conhecimento intelectual deveria levar a ação e, a ação, do mesmo modo, levar ao conhecimento intelectual. Há espaço, então, somente para o coletivo, já que agir individualmente possui muitos traços de dissidência. As reivindicações do 'eu' são vistas pelo governo como egoístas e, portanto, são inimigas da causa social.

Dentro da estética fotográfica é interessante notar que a linha do horizonte permanece tranquila, calma, como se pudéssemos estender essa característica ao 
futuro morto, assim ele tem como única escolha o céu, a própria calma. Ele pode também ser observado como o plano alto, nobre, o qual não se ajoelhará. Aqui há uma perspectiva bem diferente da cristã ocidental, para a qual o ajoelhar-se poderia muito bem ser um modo de chegar aos céus. Existe então uma altivez, típicas dos heróis que não perdem a coragem diante da morte e de certa forma morrem ainda lutando, mostrando seu valor, sem permitir que seus opositores se apresentem como superiores, podendo até ser altos ou supostamente grandiosos, mas não possuem valores verdadeiros. A altura dos algozes representa o poder não só do executor, como de todo o governo, um poder que vem pela característica física, pelo poderio bélico com que domina corpos e pensamentos, não havendo jamais nenhuma virtude.

A impossibilidade de expressar-se como oposição ou até mesmo como oposição leal obriga os críticos a viverem na clandestinidade, fato que lhes dá sempre um ar de conspiração. Para que um governante mantenha-se no poder é preciso que tenha astúcia entre seus traços de personalidade, assim desconfiará e eliminará os dissidentes. No poema, porém, Bei Dao procura retirar o valor positivo que haveria nesta esperteza dos poderosos, quando não se ajoelha diante dos assassinos o eu-lírico deseja demonstrar que aqueles que ordenaram a sua morte não são merecedores de admiração e nem de sua lealdade. Ao fazer esta recusa o poeta está questionando o conceito clássico de piedade filial de Confúcio, o qual foi estendido pela política como submissão também aos governantes, como se as qualidades para governar fossem intrínsecas e, por isso, inquestionáveis. É interessante notar aqui que o poeta não respeita a dimensão política deste conceito, entretanto continua adotando-o em sua dimensão familiar, já que faz de sua mãe sua herdeira, quem recebe seu instrumento mais precioso, em oposição aos carrascos. Essa altivez do eu-lírico, porém, é inútil diante da ignorância que o matará, o que acaba por causar um amanhecer escarlate, vermelho como o partido comunista, vermelho como a guarda vermelha, como o sangue, que agora derramado, traz as más previsões de continuidade. O futuro está manchado, perdido, tingido de sangue. Sangue que flui espalhando-se através de um silêncio anunciado pela ausência de testamento e através do qual se percebe a força do título que fala em 'anunciação', em uma morte anunciada, em uma tragédia anunciada e um fluir anunciado. Além disso, pensando em Yu Luoke, veem-se os tempos mais difíceis após sua morte e prevendo isto é que ele tentou transformar alguma coisa com o seu tratado, como tenta fazer agora Bei Dao.

O tom profético do poema vem da boca de um herói que não deveria ter de assumir esta posição, que está preocupado com o futuro da alienação praticada pelo poder político e também com os abusos de seus algozes. O mais interessante 
é que Bei Dao faz isso se apropriando da figura do mártir nacional Yu Luoke e construindo assim, um argumento de autoridade para seu discurso, o que dá força ao seu modo de subjetivação; técnicas e criatividades que entre outras, que vão lhe valer o direito de ser atualmente estudado nas escolas chinesas.

\section{Anunciaçáo}

Para Yu Luoke, o mártir
宣告

$$
\text { xuāngào }
$$

- 一给遇罗克烈士

gě̀ Yù Luókè lièshì

Bèidăo
Talvez a última das horas tenha finalmente chegado

Eu não deixo testamento

somente uma caneta, para minha mãe.

Eu nem serei um herói

em uma era sem heróis,

eu só desejo ser um homem.

A tranquila linha do horizonte

dividiu as filas de viventes e moribundos

eu só posso escolher o céu

de maneira nenhuma ajoelhar-me sobre o chão

permitindo a exibição da altura dos algozes.
也许最后的时刻到了

yěshǔ zuibòn de shíkè dào le

我没有留下遗嘱

wǒ méi yǒn liúxià yíz̧̧ŭ

只留下笔, 给我的母亲

zh̆̌ liúxià b̆g gěi wǒde mŭqin

我并不是英雄

wǒ bìng bù sbìyingxióng

在没有英雄的年代里,

zài méi yǒu yingxióng de niándài lĩ

我只想做一个人。

wǒ zhĭ xiăng zuò yĩ gè rén

宁静的地平线

ningìng de dipingxiàn

分开了生者和死者的行列

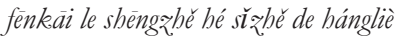

我只能选择天空

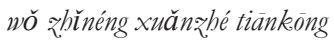

决不跪在地上

juébù guì zài dìshang

以显出刽子手们的高大

y̌ xiănchü guĩishbŏu men de gāodà

2 Todas as referências à pronúncia feitas neste trabalho tem como base o Mandarim. 
Para obstruir a liberdade do vento

vindo do buraco de bala das estrelas

fluirá o sangue escarlate do amanhecer.
好阻挡自由的风

băo žŭdăng zìyón de fèng

\section{从星星的弹孔里}

cóng xingxing de dànköng lĩ

将流出血红的黎明

jï̄ng liúchü xuèbóng de liming

\section{Referências}

FAIRBANK, John King; GOLDMAN, Merle. “O Grande Salto para Frente 1958-1960”, "A Revolução Cultural 1966-1976”. In: China: uma nova história, tradução de Marisa Motta. Porto Alegre: L\&PM, 2008, pp. 339-371.

GOLDBLAT'T, Howard; M., Joseph S. The Columbia Anthology of Modern Chinese Literature. New York: Columbia University Press, 1983, pp. xxx e 576.

LI, Ku Cheng. "Yu Luoke". In: A Glossary of Political Terms of the People's Republic of China. Columbia University, pp. 548. Página eletrônica: http://books.google.com.br/ books?id=J5QbQpQTegwC\&pg $=$ PA548\&lpg $=$ PA 548\&dq $=$ yu+luoke\&source $=$ bl\&ots $=$ qoCJm-Zxqb\&sig=asVxEythOmOXUUevC2OFbl5KYFE\&hl=pt-BR\&sa=X\&ei=reOs UI69FIrq9ASYzoGICA\&ved=0CD4Q6AEwAg\#v $=$ onepage $\& q=y u \%$ 20luoke $\& f=$ false . Consulta realizada em 6 de novembro de 2012.

YEH, Michelle. "Introduction: From the Margin". In: Anthology of Modern Chinese Poetry. Yale University Press, 1993, pp. XXXIII - L.

YEH, Michelle. "On English Translation of Modern Chinese Poetry”. In: EOYANG, Eugene; LIN, Yao-fu. Translating Chinese Literature. Indiana University Press, 1995, pp. 275-291. ZHAO, Zhenkai (Bei Dao 北岛). “宣告 Xuāngào”. Página eletrônica: http://wenku.baidu. com/view/3399dca50029bd64783e2c57.html. Consultado em 28 de outubro de 2012. 